(6)

OPEN ACCESS

Department of Marketing and Consumer Studies, University of Guelph, Guelph, Ontario,

Canada

${ }^{2}$ Dan Program in Management and Organizational Studies, University of Western Ontario, London, Ontario, Canada

Correspondence to Professor Timothy Dewhirst, Department of Marketing and Consumer Studies, College of Business and Economics, University of Guelph, Guelph, Ontario N1G 2W1, Canada; dewhirst@uoguelph.ca

Published Online First 7 April 2017

\title{
Lamborghini brand sharing and cigarette advertising
}

Timothy Dewhirst, ${ }^{1}$ Wonkyong Beth Lee²

\section{LAMBORGHINI BRAND SHARING AND CIGARETTE ADVERTISING}

Licensing and brand sharing arrangements, where a fee or royalty is paid for use of a name, is a common strategic consideration to provide a newly introduced product or service with an immediate and proven brand identity (table 1). ${ }^{1}$ Serving as such an example, Korean Tomorrow and Global (KT\&G), which is South Korea's leading tobacco firm, launched a new cigarette brand, Tonino Lamborghini, on 18 April 2012, where the branding resembles the legendary Italian luxury sports car maker (figure 1A,B). ${ }^{2}{ }^{3}$ According to The Moodie Report, it took 1 year of negotiation to reach a brand licensing agreement and 3 years to develop the cigarette product. ${ }^{4}$ The cigarette brand was initially offered in two variants, L8 (predominantly black package) and L6 (predominantly yellow package), with reported tar deliveries of $8.0 \mathrm{mg}$ and $6.0 \mathrm{mg}$, respectively. Compared with KT\&G's other product offerings, Tonino Lamborghini cigarettes have considerably higher reported tar deliveries and such product characteristics contribute to the brand's masculine, powerful and assertive image..$^{4-8}$ Tonino Lamborghini now offers additional brand variants, including 'Ice Volt' (figure 2), which is mentholated and has promotional claims that the product possesses 'the thrilling taste of powerful cooling freshness,' and 'Ice Tornado,' which is described as having a strong, fresh and cool flavour and possesses a 'tornado' filter that rapidly rotates cigarette smoke (figure 3).

The brand name, Tonino Lamborghini refers to the son of Ferruccio Lamborghini, who is the founder of the legendary car manufacturer. Tonino Lamborghini's signature is depicted on the packaging, which is highly expressive of an identity and meant to give the

\begin{tabular}{ll}
\hline Table 1 & Key terms and definitions \\
\hline Term & Definition \\
\hline Branding & $\begin{array}{l}\text { The use of a name or logo to identify and give } \\
\text { differentiated meaning to a product. }\end{array}$ \\
Brand equity & $\begin{array}{l}\text { Enhancing the value of a brand based on } \\
\text { elements such as brand awareness, perceived } \\
\text { brand quality, brand associations and brand } \\
\text { loyalty. }{ }^{14}\end{array}$ \\
Brand licensing & $\begin{array}{l}\text { 'Renting the brand equity to another company, } \\
\text { which benefits from the association.' }\end{array}$ \\
Brand sharing & $\begin{array}{l}\text { 'When a brand name, emblem, trademark, logo } \\
\text { or trade insignia or any other distinctive feature } \\
\text { (including distinctive colour combinations) on } \\
\text { a non-tobacco product or service is connected } \\
\text { with a tobacco product or tobacco company } \\
\text { in such a way that the tobacco product or } \\
\text { company and the non-tobacco product or } \\
\text { service are likely to be associated.' }{ }^{22}\end{array}$ \\
\hline
\end{tabular}
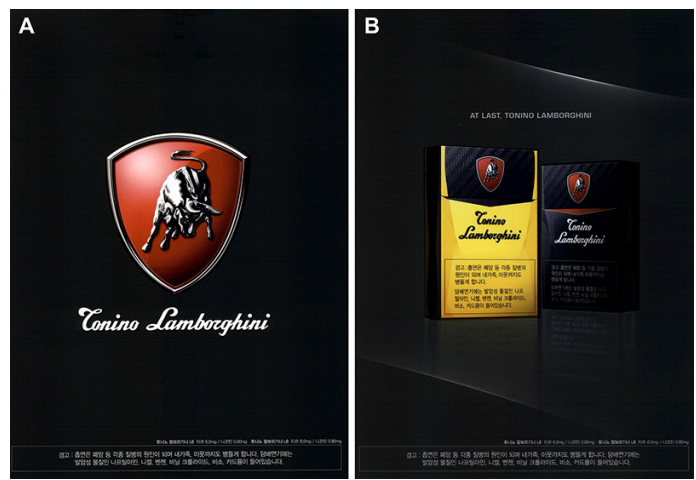

Figure 1 (A, B) A two-page Tonino Lamborghini cigarette ad, from the Korean edition of Esquire (July 2012 issue), that appeared on successive right-side pages on glossy, heavier and higher quality paper relative to most pages seen within the magazine. The ad circulated a few months after the cigarette brand's launch.

product authenticity. ${ }^{10}$ Tonino Lamborghini is also known as an Italian merchandising brand that offers fashion items as well as tobacco paraphernalia such as high-end lighters, cases, cigar cutters and ashtrays. ${ }^{11}$ Like its automobile counterpart, a raging bull logo is used to represent Tonino Lamborghini cigarettes (figure 4). A bull represents a powerful, impressive, striking and daunting beast that also symbolises strength, masculinity, virility and regality. 1213

Choi Jihyun, KT\&G Overseas Brand Department Manager, explains that the tobacco company is attempting to leverage the masculine global appeal of the Lamborghini brand name, which is most likely to attract or draw Korea's younger generation male smokers who are particularly interested in western culture and imported luxury brands and cars. Tonino Lamborghini is marketed to have a premium and masculine brand image, targeting
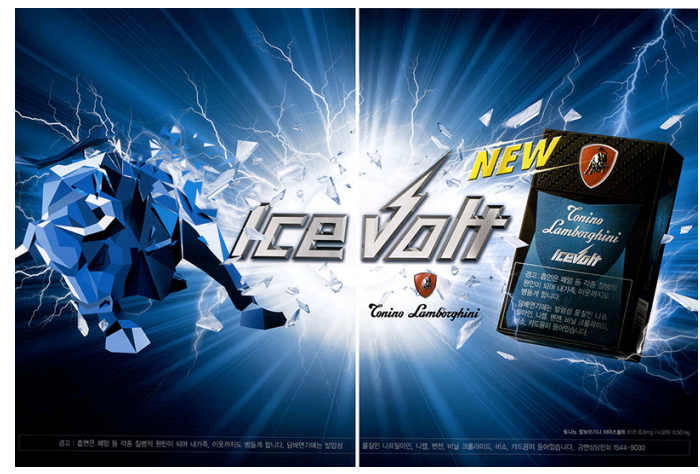

Figure 2 A double-page ad, from 2012, that identifies the Tonino Lamborghini brand variant 'Ice Volt' as 'new.' 


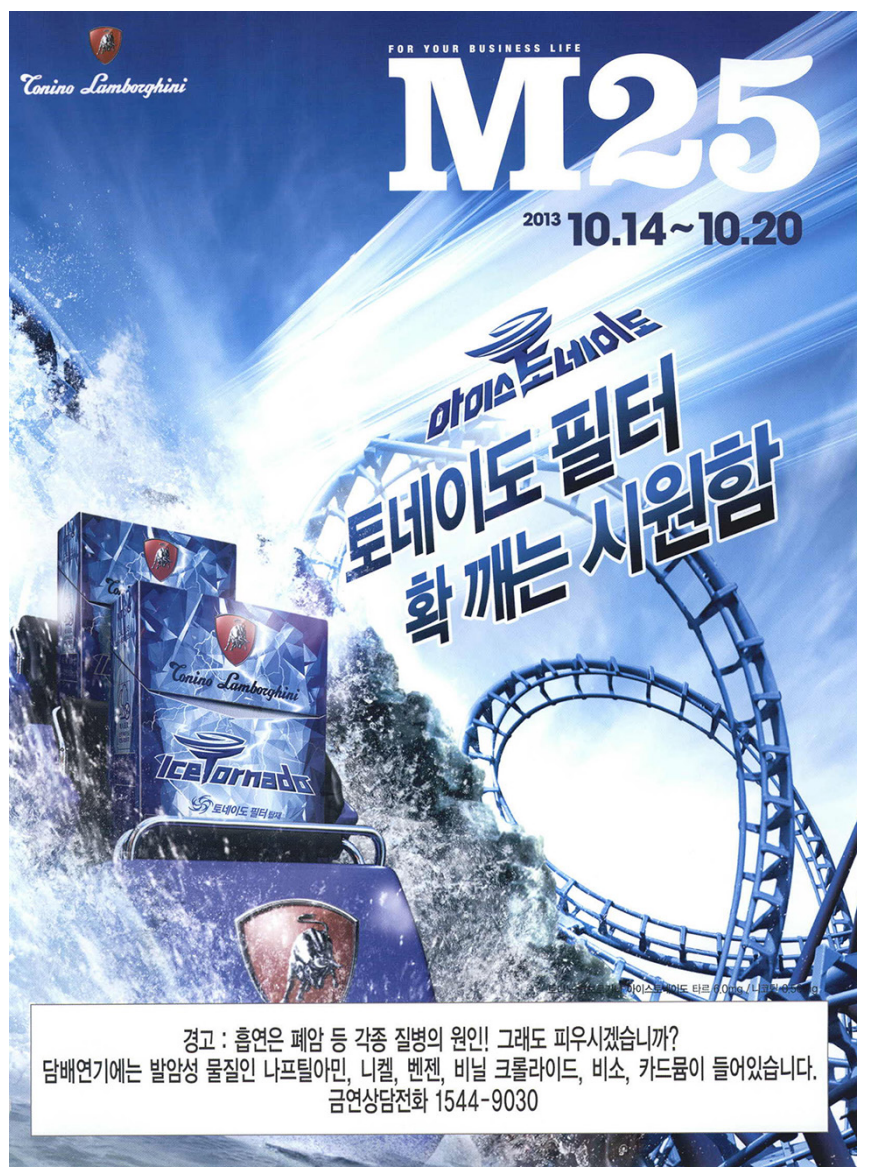

Figure 3 From 2013, a Tonino Lamborghini ad for the 'Ice Tornado' brand variant that circulated in the lifestyle magazine M25. The ad copy, in Korean, states the Ice Tornado brand name and refers to the variant's 'tornado' filter and a coolness sensation that wakes you up and provides alertness (ie, provides a jolt).

the 'assertive, competent and refined' man in possession of the 'Lamborghini charisma." ${ }^{4}$ Moreover, cars such as Lamborghini are regarded as expressions of excitement, as well as being flashy and spirited. ${ }^{14}$ Accordingly, the packaging of Tonino Lamborghini cigarettes uses bold colours and graphics. Lamborghini cars are globally recognised for sensational speed and unique style (eg, the doors open upward rather than outward), as well as luxury, sophistication and innovation.

Domestically, the launch of Lamborghini cigarettes-given the brand's higher reported tar deliveries; masculine, powerful and premium image; and youthful appeal-appears to be competitively positioned against Marlboro, which is the most popular cigarette brand globally. Nevertheless, KT\&G's growth is increasingly dependent on exports to overseas markets. ${ }^{15}$ Despite being the leading tobacco company in South Korea, which is the world's eighth largest cigarette market, KT\&G's export sales now exceed its domestic sales. ${ }^{16}{ }^{17} \mathrm{KT} \& \mathrm{G}$ has acquired the 'exclusive global sales rights for the (Tonino Lamborghini) cigarette brand and plans to market it as one of its global strategic items. ${ }^{3}$ Since 2012, Tonino Lamborghini has been exported to 17 countries including China (duty-free shops), Russia and the Middle East. ${ }^{18-20}$

The Lamborghini brand sharing example provides evidence that important obligations of the WHO Framework Convention on Tobacco Control (FCTC), which is legally binding and has been ratified by 180 Parties to date, including the Republic of

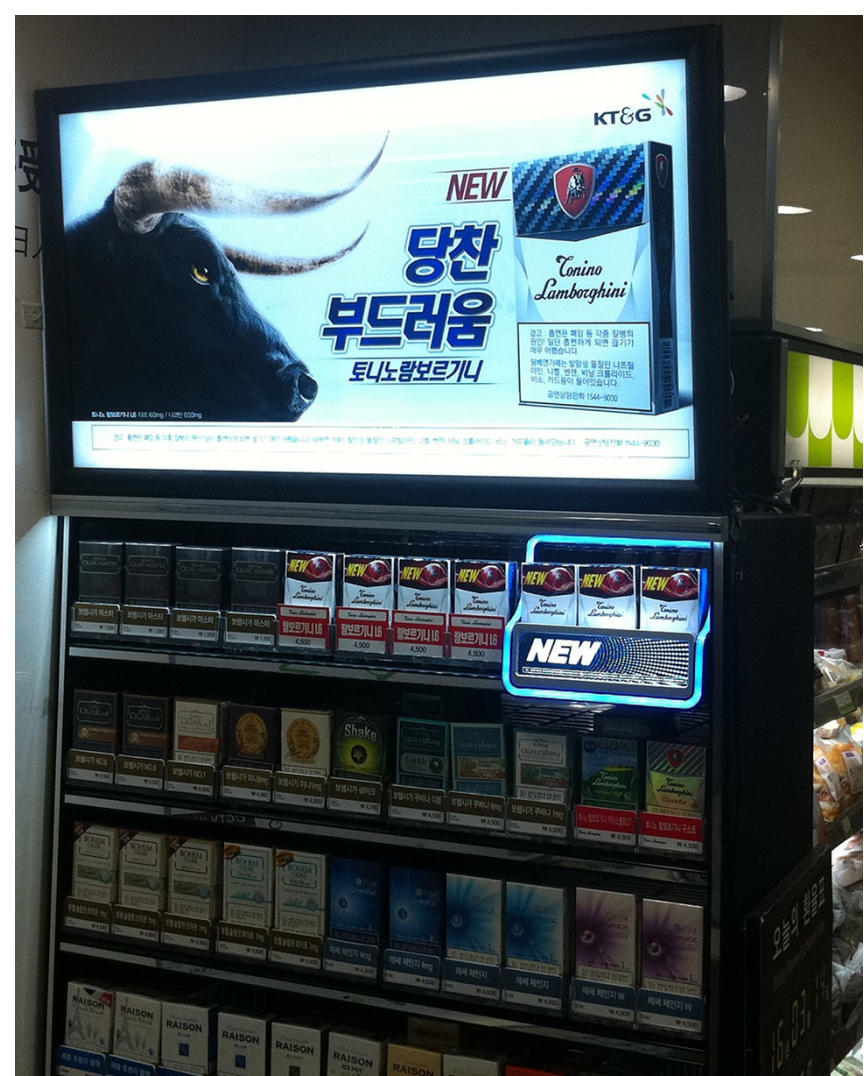

Figure 4 A photograph of point-of-sale signage situated among the 'power wall' of a convenience store. The ad copy, in Korean, states the Tonino Lamborghini brand name and refers to smoothness as well as confidence and assertiveness. The price of Tonino Lamborghini cigarettes is listed at $\$ 4500$ (nearly US\$4.00), which reflects a premium price point and the same price listing as direct competitor, Marlboro, although it is acknowledged that the price range of cigarettes tends to be minimal in South Korea. The photo, dated 14 March 2016, was taken by Timothy Dewhirst.

Korea, are not being fulfilled. Brand sharing is identified as a form of tobacco advertising and promotion covered by stipulations of the WHO FCTC and defined within guidelines for implementation of Article 13.

Acknowledgements The authors thank Dr Joanna Cohen and two anonymous reviewers for their helpful feedback and supportive comments. When writing this manuscript, TD and WBL were visiting scholars (adjunct professors) at Hanyang University's Department of Advertising and Public Relations in South Korea.

Contributors TD and WBL significantly contributed to the writing and analysis of the study.

Funding This work was supported by an award from the Institute for Global Tobacco Control at the Johns Hopkins Bloomberg School of Public Health with funding from the Bloomberg Initiative to Reduce Tobacco Use.

Competing interests TD is an associate editor of Tobacco Control with respect to Product Marketing and Promotion. He has served as an expert witness in tobacco litigation and served as an invited expert and consultant for establishing Article 13 guidelines of the WHO FCTC.

Provenance and peer review Not commissioned; externally peer reviewed.

Open Access This is an Open Access article distributed in accordance with the Creative Commons Attribution Non Commercial (CC BY-NC 4.0) license, which permits others to distribute, remix, adapt, build upon this work non-commercially, and license their derivative works on different terms, provided the original work is properly cited and the use is non-commercial. See: http://creativecommons.org/licenses/by-nc/4.0

(c) Article author(s) (or their employer(s) unless otherwise stated in the text of the article) 2018. All rights reserved. No commercial use is permitted unless otherwise expressly granted. 


\section{REFERENCES}

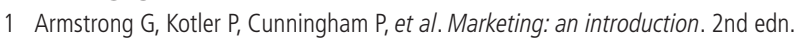
Toronto, ON: Pearson Prentice Hall, 2007.

2 Whan-woo Y. KT\&G dominates cigarette market. The Korea Herald; 26 March 2013.

3 KT\&G rolls out 'Lamborghini' cigarette. The Korea Herald; 4 April 2012.

$4 \mathrm{Ng} \mathrm{M.} \mathrm{KT \& G}$ targets new markets with Tonino Lamborghini cigarettes. The Moodie Report; 2012.

5 Dewhirst T, Lee WB. Cigarette advertising in the Republic of Korea: a case illustration of The One. Tob Control 2012;21:584-8.

6 National Cancer Institute. The role of the media in promoting and reducing tobacco use. smoking and tobacco control monograph No. 19. Bethesda, MD: US Department of Health and Human Services, National Institutes of Health, National Cancer Institute, 2008.

7 Dewhirst T, Sparks R. Intertextuality, tobacco sponsorship of sports, and adolescent male smoking culture: a selective review of tobacco industry documents. J Sport Soc Issues 2003;27:372-98.

8 Cook BL, Wayne GF, Keithly L, et al. One size does not fit all: how the tobacco industry has altered cigarette design to target consumer groups with specific psychological and psychosocial needs. Addiction 2003;98:1547-61.

9 KT\&G PR Center. Ice tornado fitted with tornado filter to be launched. KT $\mathscr{G} G$ News 2013

10 Kettle KL, Häubl G. The signature effect: signing influences consumption-related behavior by priming self-identity. J Cons Res 2011;38:474-89.
11 Joseph N. Lamborghini's raging bull logo to adorn cigarettes in South Korea. Autoblog 10 April 2012.

12 Forty S. Symbols. San Diego, CA: Thunder Bay Press, 2003.

13 Shepherd R, Shepherd R. 1000 symbols: what shapes mean in art and myth. London: Thames \& Hudson, 2002.

14 Aaker DA. Managing brand equity: capitalizing on the value of a brand name. New York: The Free Press, 1991.

15 Mitchell H. KT\&G: masters of the super slim. Tobacco Asia; 19 April 2010.

16 Hyon-hee S. BAT Korea eyes premium cigarette market in Korea. The Korea Herald; 29 August 2011.

17 Lee H. KT\&G sells more cigarettes abroad than home. The Korea Times; 18 January 2016.

18 Chung J. KT\&G to launch Tonino Lamborghini overseas. The Korea Herald; 19 November 2012.

19 Anon KT\&G to export "Tonino Lamborghini" to Hong Kong. The Korea Economic Daily 20 November 2012

20 Kim M. KT\&G rolls out Tonino Lamborghini Ice Volt GT. Business Korea 9 July 2015.

21 Duncan T. Principles of advertising and IMC. 2nd edn. New York: McGraw-Hill Irwin, 2005:95.

22 World Health Organization. Elaboration of guidelines for implementation of Article 13 of the convention. WHO Framework Convention on Tobacco Control. Conference of the Parties to the WHO Framework Convention on Tobacco Control, Third Session, Durban, South Africa; 5-6 November 2008; 17-22. 